\title{
Metformin reduces insulin resistance and the tendency toward hyperglycaemia and dyslipidaemia in dogs with hyperadrenocorticism
}

\author{
Diego Daniel Miceli ${ }^{1,2}$, Patricia Noemi Vidal ${ }^{1}$, María Fernanda Cabrera Batter ${ }^{1}$, Omar Pignataro $^{2}$ \\ and Victor Alejandro Castillo,"* \\ ${ }^{1}$ Universidad de Buenos Aires, Facultad de Ciencias Veterinarias, Cátedra de Clínica Médica de Pequeños \\ Animales y Hospital Escuela de Medicina Veterinaria, Unidad de Endocrinología, Av. Chorroarín 280, Buenos \\ Aires CP 1427, Argentina \\ ${ }^{2}$ Laboratorio de Endocrinología Molecular y Transducción de Señales, Instituto de Biología y Medicina \\ Experimental-CONICET, Vuelta de Obligado 2490, Buenos Aires CP 1428, Argentina
}

\begin{abstract}
Hypercortisolism induces a state of insulin resistance that can occur concurrently with fasting hyperglycaemia, dyslipidaemia and diabetes mellitus. Metformin reduces hepatic glucose production and insulin resistance of the skeletal muscle and adipose tissue. The aim of this study was to evaluate the effects of metformin on the control of metabolic disorders of dogs with hyperadrenocorticism (HAC). Twenty-three dogs with HAC were randomly divided into two groups, consisting of a control group and a metformin group (10 mg metformin $/ \mathrm{kg} / 12 \mathrm{~h}$ ). Both groups received the same treatment for HAC. At baseline and 3 months, blood glucose, total cholesterol, triglycerides and insulin concentrations, in addition to urinary cortisol:creatinine ratio, Homeostatic Model Assessment (HOMA) for insulin sensitivity and $\beta$-cell function were measured. Dogs treated with metformin showed significantly reduced glycaemia, cholesterolaemia and triglyceridaemia. They also presented reduced hyperinsulinism and insulin resistance, as well as improved pancreatic $\beta$-cell function. The implementation of metformin as an adjuvant therapy is effective for the normalisation of metabolic disorders of dogs with HAC.
\end{abstract}

Keywords: Dyslipidaemia, Hyperadrenocorticism, Insulin resistance, Metformin.

\section{Introduction}

Cortisol antagonises various functions of insulin, and high levels may predispose an individual to insulin resistance, a condition in which the peripheral tissues have a reduced response to insulin (Andrews and Walker, 1999; Miceli et al., 2014; Mazziotti et al., 2017). Indeed, the antagonism of insulin by cortisol is so potent that the glucocorticoid effects are referred to as "diabetogenic" (Van Raalte et al., 2009; Van Raalte and Diamant, 2014). Chronic hypercortisolism stimulates hepatic gluconeogenesis, interfering with the insulin signalling cascade and glucose uptake in the skeletal muscle and adipose tissue, in addition to affecting the insulin synthesis and secretion of pancreatic $\beta$-cells, as well as inducing their apoptosis (Schäcke et al., 2002; Vegiopoulos and Herzig, 2007). These metabolic disorders are clinically characterised by fasting hyperglycaemia, hypercholesterolaemia, hypertriglyceridaemia, abdominal obesity, hepatic steatosis and diabetes mellitus (Peterson et al., 1984; Pivonello et al., 2010; Di Dalmazi et al., 2012). Between $5 \%$ and $22 \%$ of dogs with HAC develop diabetes mellitus (Peterson et al., 1981; Nichols, 1994; Ishino et al., 2010; Gomes Pöppl et al., 2016; Miceli et al., 2017).
Homeostatic Model Assessment indices (HOMA) are used to evaluate both peripheral insulin sensitivity $\left(\mathrm{HOMA}_{\text {insulin sensitivity }}\right)$ and the function of pancreatic $\beta$ cells to produce insulin $\left(\mathrm{HOMA}_{\beta \text {-cell function }}\right.$ ) (Matthews et al., 1985; Verkest et al., 2010; Miceli et al., 2014). Metformin is a biguanide that is commonly used as an oral antidiabetic medication for the treatment of type 2 diabetes mellitus in humans (Herman et al., 2005; Aroda et al., 2015; American Diabetes Association, 2016). Metformin reduces hepatic glucose production and insulin resistance in peripheral tissues (especially the skeletal muscle and adipose tissue), therefore, metformin is considered an "insulin-sensitising" drug (Natali and Ferrannini, 2006).

The effects of metformin are not immediate as it acts by modifying the gene expression of key enzymes involved in metabolic regulation (Foretz et al., 2014). In the liver, metformin inhibits gluconeogenesis and glycogenolysis, and stimulates glycogenesis (Zhou et al., 2001). In the adipose tissue and skeletal muscle, metformin increases the number and affinity of insulin receptors, the tyrosine kinase activity of the insulin receptor, and the translocation and intrinsic activity of GLUT-4 (glucose transporter type 4) (Natali and Ferrannini, 2006; Geerling et al., 2014). 
In veterinary medicine, metformin can be used to treat cats with diabetes mellitus, but only in cases where the patient has a functional reserve of pancreatic $\beta$-cells (Nelson et al., 2004). In dogs, experimental studies have been performed to evaluate the hepatic effects of metformin (Chu et al., 2000), but it is not routinely used as a treatment. In dogs with $\mathrm{HAC}$, the effects of metformin treatment remain unknown. The purpose of this study was to evaluate the therapeutic actions of metformin for controlling the tendency toward hyperglycaemia, hypercholesterolaemia, hypertriglyceridaemia, hyperinsulinism and insulin resistance in dogs with HAC.

\section{Study population}

\section{Materials and Methods}

Twenty-three dogs $(n=23)$ with pituitary-dependant hyperadrenocorticism $(\mathrm{PDH})$ were studied. The diagnosis of PDH was based on history (polydypsia, polyuria and polyphagia, panting, persistent anestrous and any other typical sign of the disease), physical examination (alopecia, prominent abdomen, thin inelastic skin, muscular atrophy), routine laboratory findings (stress leukogram, mild hyperglycaemia, dyslipidaemia, increased alkaline phosphatase or alanine transferase, low urine specific gravity) and an increased urine cortisol:creatinine ratio (UCCR) in two consecutive morning urine samples collected by the owner at home. After collection of the second urine sample, three doses of dexamethasone $(0.1 \mathrm{mg} / \mathrm{kg})$ were administered PO at 8-hour intervals, and a third urine sample was collected the following morning, according to Kooistra and Galac (2012). The diagnosis was further supported by visualisation of the adrenal glands by ultrasonography and the pituitary gland by nuclear magnetic resonance imaging. Abdominal ultrasonography revealed bilateral adrenal hyperplasia and no evidence of an adrenocortical tumor in any of these 23 dogs. Nuclear magnetic resonance imaging revealed a pituitary mass in all dogs. Dogs with an infectious disease (systemic or local), pancreatitis, diabetes mellitus, hypothyroidism, tumours (except pituitary adenoma) or any other systemic disorder capable of inducing insulin resistance were excluded (Hess, 2010). Also, dog with abnormalities on Complete Blood Count (CBC), urinalysis or biochemical profile other than those expected with PDH (stress leukogram, low urine specific gravity, mild hyperglycaemia, dyslipidaemia, increased alkaline phosphatase or alanine transferase), were excluded. Likewise, no dog with increased Blood Urea Nitrogen (BUN) was included. In all cases, the common therapy used in Argentina was administered, consisting of combined treatment with cabergoline $(0.07$ $\mathrm{mg} / \mathrm{kg} /$ week, divided into doses administered every 48 hours) and ketoconazole $(20 \mathrm{mg} / \mathrm{kg}$ administered every 24 hours) (Castillo et al., 2008; Lien and Huang, 2008).
The 23 dogs with HAC were randomly divided into two groups: (1) control group $(\mathrm{n}=10$; six females and four males; all were non-castrated; median age of 8.5 years, range 6 to 14 years); or (2) metformin group $(n=13$; eight females and five males; two castrated females; median age of 9 years, range 7 to 13 years), for which metformin was administered at a dose of $10 \mathrm{mg} / \mathrm{kg}$ every 12 hours with food. In cases of intolerance, metformin was administered gradually (first week: 2.5 $\mathrm{mg} / \mathrm{kg} / 12 \mathrm{~h}$, second week: $5 \mathrm{mg} / \mathrm{kg} / 12 \mathrm{~h}$, third week: $7.5 \mathrm{mg} / \mathrm{kg} / 12 \mathrm{~h}$, and finally the total dose of 10 $\mathrm{mg} / \mathrm{kg} / 12 \mathrm{~h}$ ). All the non-castrated females had low progesterone levels $(<2 \mathrm{nmol} / \mathrm{L})$, both at the beginning and at the end of the treatment (data not shown), so that the progesterone insulin antagonism was ruled out. None of the dogs showed any clinical signs or biochemical abnormalities (both serum and urine) characteristic of liver or kidney disease that might have exacerbated the adverse effects of metformin.

\section{Hormone and biochemical measurements}

Glucose, triglycerides, total cholesterol, insulin and UCCR were measured. Blood samples were collected at the same time for all dogs after a 12-hour fast from solid food, both at the time of diagnosis (basal time point) and 3 months after starting treatment. Blood glucose was assessed using an automated laboratory method (Metrolab Autoanalyzer; Merck, Germany) according to the manufacturer's instructions. Blood samples for glucose analysis were collected in glass tubes containing sodium fluoride and EDTA as the anticoagulant (Anticoagulant G; Wiener Laboratory, Argentina). Blood samples for triglycerides and total cholesterol analysis were collected in another tube and measured by an automated laboratory method (Metrolab Autoanalyzer; Merck), according to the manufacturer's instructions.

Insulin concentrations were measured by a specific Enzyme-Linked ImmunoSorbent Assay (ELISA) for dogs and pigs (Porcine/Canine Insulin ELISA; Alpco, USA), with intra- and interassay variation coefficients (canine performance) of $4.2 \%$ and $4.3 \%$, respectively, and sensitivity of $0.007 \mathrm{ng} / \mathrm{mL}$.

Urine cortisol was measured by radioimmunoassay (RIA) using a commercial kit (DPC Corporation, San Diego, CA, USA). The inter- and intra-assay coefficients of variation for cortisol were $8 \%$ and $5 \%$, respectively. Creatinine was measured by an automated method (Metrolab Autoanalyzer; Merck) according to the manufacturer's instructions.

\section{HOMA for insulin sensitivity and $\beta$-cell function}

Both fasting insulin sensitivity and the role of pancreatic $\beta$-cells were assessed by HOMA. The $\mathrm{HOMA}_{\text {insulin }}$ sensitivity and $\mathrm{HOMA}_{\beta \text {-cell function were }}$ calculated with nonlinear formulas (Levy et al., 1998) using HOMA Calculator version 2.2.2 (Diabetes Trial Unit, University of Oxford, UK; 
http://www.dtu.ox.ac.uk/index.php?maindoc_homa/) according to the methods previously described (Verkest et al., 2010; Miceli et al., 2014). In those cases in which insulin concentrations exceeded the maximum value allowed by the HOMA calculator, the mathematical formula (Matthews et al., 1985) was used to calculate the aforementioned indices:

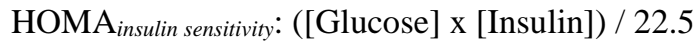

HOMA $_{\beta}$-cell function: $(20 \mathrm{x}$ [Insulin] / [Glucose] - 3.5)

Statistical analysis

The intra- and intergroup comparisons were performed using nonparametric tests, the Wilcoxon rank test and Mann-Whitney U test, respectively. Data are expressed as the median and interquartile range. The level of significance was set at $\mathrm{P}<0.05$. The statistical analysis were performed using GraphPad Prism 6.0 software (GraphPad software Inc.).

\section{Ethical approval}

The Ethics Committee of the Faculty of Veterinary Science (CICUAL) and the Office of Science at the University of Buenos Aires approved the present study, according to the laws on experimentation in animals in Argentina, as well as the recommendations of the World Health Organization. Signed consent was obtained from the owners of all dogs prior to their participation in this project.

\section{Clinical appearance}

\section{Results}

In $5 / 13$ dogs treated with metformin (38.46\%), we observed some degree of drug intolerance. The most common adverse effects were gastrointestinal symptoms, including diarrhoea, inappetence and vomiting. Diarrhoea was the most frequently observed adverse effect. In these five cases, metformin was administered at gradually increasing doses, progressing from $2.5 \mathrm{mg} / \mathrm{kg} / 12 \mathrm{~h}$ during the first week, then 5 $\mathrm{mg} / \mathrm{kg} / 12 \mathrm{~h}$, then $7.5 \mathrm{mg} / \mathrm{kg} / 12 \mathrm{~h}$, and finally the total dose of $10 \mathrm{mg} / \mathrm{kg} / 12 \mathrm{~h}$. No dogs were excluded from the study, and none showed signs of lactic acidosis. No dogs developed diabetes mellitus, at least during the first 3 months of treatment.

\section{Blood glucose, triglycerides and total cholesterol concentrations}

When comparing the basal time blood glucose [control group: median $5.93 \mathrm{mmol} / \mathrm{L}$ (interquartile range $4.1-$ 6.2), metformin group: $6.38 \mathrm{mmol} / \mathrm{L}$ (5.3-6.9)], triglycerides [control group: $1.6 \mathrm{mmol} / \mathrm{L}$ (1.3-2.6), metformin group: $2.3 \mathrm{mmol} / \mathrm{L}$ (1.9-3.7)] and total cholesterol concentrations [control group: $7.8 \mathrm{mmol} / \mathrm{L}$ (6.1-11.5), meformin group: $9.9 \mathrm{mmol} / \mathrm{L}$ (7.3-12.3)] between the groups, no significant differences were observed (Fig. 1 and 2). In the metformin group, blood glucose $(\mathrm{P}<0.01)$, triglycerides $(\mathrm{P}<0.05)$ and total cholesterol $(\mathrm{P}<0.01)$ concentrations were significantly reduced after 3 months of treatment (Table 1).
Table 1. Blood glucose, triglycerides, total cholesterol and insulin concentrations and urine cortisol:creatinine ratio (UCCR) in dogs with hyperadrenocorticism (with or without metformin) at basal time and after 3 months of treatment.

\begin{tabular}{lcccc}
\hline & \multicolumn{2}{c}{ Control group } & \multicolumn{2}{c}{ Metformin group } \\
\cline { 2 - 5 } Parameter & Basal & 3 months & Basal & 3 months \\
\hline Glucose & 5.93 & 5.71 & 6.38 & $4.76^{* *, a}$ \\
(mmol/L) & $(4.1-6.2)$ & $(5.2-6.8)$ & $(5.3-6.9)$ & $(4.1-5.5)$ \\
Triglycerides & 1.6 & 2.0 & 2.3 & $1.1 *, \mathrm{~b}$ \\
(mmol/L) & $(1.3-2.6)$ & $(1.6-2.6)$ & $(1.9-3.7)$ & $(0.7-1.8)$ \\
Total & 7.8 & 7 & 9.9 & $7.2^{* * *}$ \\
cholesterol & $(6.1-11.5)$ & $(5.6-7.8)$ & $(7.3-12.3)$ & $(6.2-10.7)$ \\
(mmol/L) & 185 & $165^{*}$ & 180 & $110^{* *, c}$ \\
$\begin{array}{l}\text { Insulin } \\
\text { (pmol/L) }\end{array}$ & $(97-406)$ & $(80-340)$ & $(90-430)$ & $(75-299)$ \\
\hline $\begin{array}{l}\text { UCCR } \\
(10-6)\end{array}$ & 74 & $15 * * *$ & 55 & $13 * * *$ \\
\hline Values & $(22.4-282)$ & $(8.5-30)$ & $(25-675)$ & $(7-280)$ \\
\hline
\end{tabular}

Values are expressed as median and interquartile range. Reference values: (Glucose: 3.36-6.72 $\mathrm{mmol} / \mathrm{L}$ ); (Triglycerides: $0.5-1.5$ $\mathrm{mmol} / \mathrm{L}$ ); (Total cholesterol: 2.6-6.5 mmol/L); (Insulin: 35.9-179.5 pmol/L); (UCCR: $\left.<10 \times 10^{-6}\right)$. Significant intragroup difference between basal and 3 months indicated by: (***: $\mathrm{P}<0.001)$; (**: $\mathrm{P}<$ $0.01)$ and $(*: \mathrm{P}<0.05)$. Significant intergroup difference at 3 months indicated by: (a: $\mathrm{P}<0.01)$; (b: $\mathrm{P}<0.05)$ and (c: $\mathrm{P}<0.05)$.

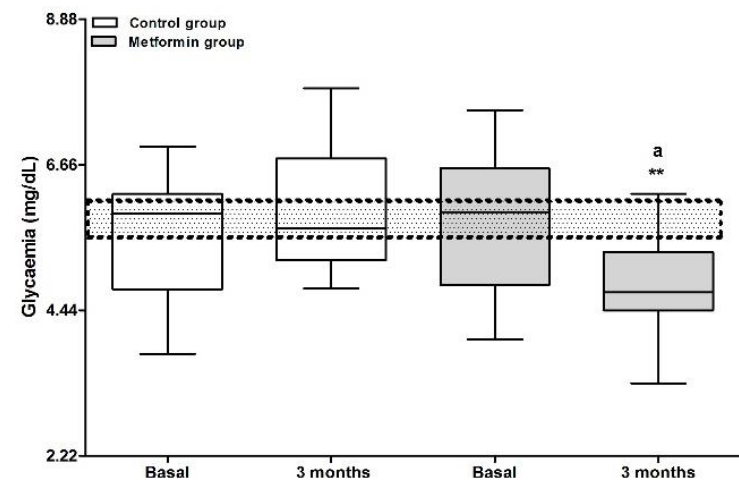

Fig. 1. Comparison of the blood glucose concentration of dogs with hyperadrenocorticism, with or without metformin treatment, at basal time and after 3 months of treatment. ** $\mathrm{P}$ $<0.01$ vs. basal time; ${ }^{a} \mathrm{P}<0.01$ vs. 3 months of control group. The dotted line indicates the glucose upper limit of the reference range $(6.72 \mathrm{mmol} / \mathrm{L})$ and into shadow area the values considering as fasting glucose intolerance.

In the control group, no significant differences were observed between the basal time measurements and those taken at 3 months for the three variables analysed. Comparing the concentrations between each group at 3 months, only blood glucose [control group: 5.71 $\mathrm{mmol} / \mathrm{L}$ (5.2-6.8), metformin group: $4.76 \mathrm{mmol} / \mathrm{L}$ (4.1-5.5)] and triglycerides concentrations [control group: $2.0 \mathrm{mmol} / \mathrm{L}$ (1.6-2.6), metformin group: 1.1 $\mathrm{mmol} / \mathrm{L}(0.7-1.8)]$ differed significantly $(\mathrm{P}<0.01$ and $\mathrm{P}<0.05$, respectively), with lower concentrations than the control group. 


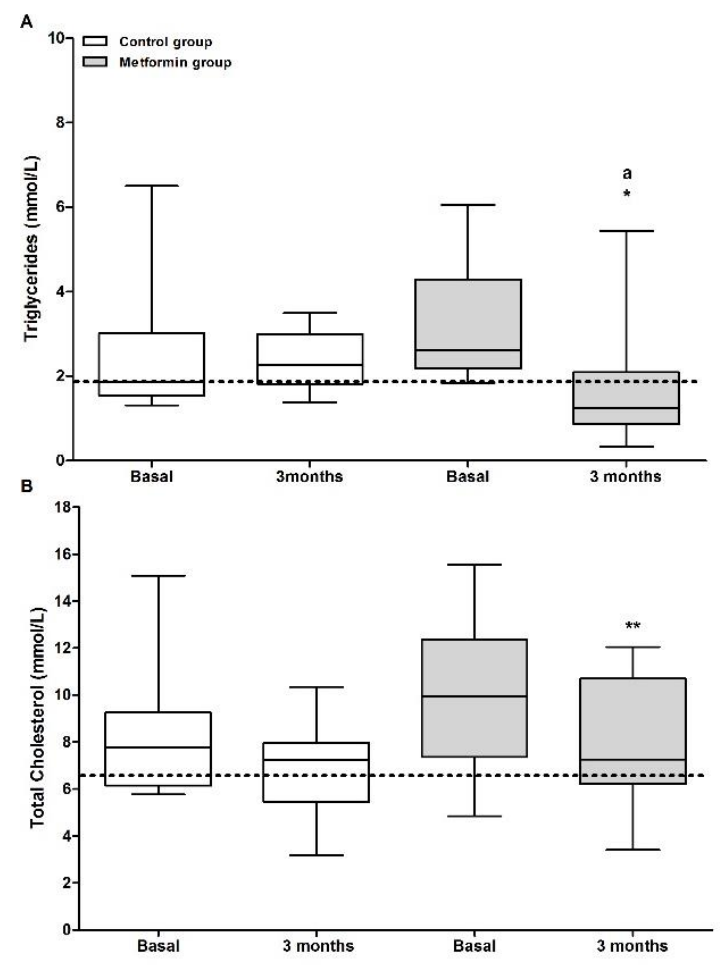

Fig. 2. Comparison of the blood triglycerides (A) and Total cholesterol (B) concentrations of dogs with hyperadrenocorticism, with or without metformin treatment, at basal time and after 3 months of tratment. A) $* \mathrm{P}<0.05$; ${ }^{\text {a }}$ $\mathrm{P}<0.05$ vs. 3 months of control group; $\mathrm{B}) * * \mathrm{P}<0.01$. The dotted line indicates the upper limit of the reference range (A: $1.5 \mathrm{mmol} / \mathrm{L}$; B: $6.5 \mathrm{mmol} / \mathrm{L}$ ).

Analysing the individual variation, the blood glucose concentration decreased in 13/13 dogs in the metformin group, and the triglycerides and total cholesterol concentrations decreased in $11 / 13$ dogs $(84.61 \%)$, with the concentrations increasing in the remaining two dogs. In the control group, blood glucose levels were decreased in 4/10 dogs (40\%), increased in 4/10 dogs (40\%) and remained constant in $2 / 10$ dogs $(20 \%)$. Triglycerides concentrations decreased in $3 / 10$ dogs $(30 \%)$, increased in $2 / 10 \mathrm{dogs}(20 \%)$ and remained constant in 5/10 dogs $(50 \%)$. Total cholesterol concentrations decreased in $5 / 10$ dogs $(50 \%)$ and remained constant in $5 / 10$ dogs $(50 \%)$ of the control group.

Insulin concentration and urine cortisol:creatinine ratio

When the basal time insulin concentrations (Fig.3) were compared amongst the groups [control group: 185 $\mathrm{pmol} / \mathrm{L}$ (97-406), metformin group: $180 \mathrm{pmol} / \mathrm{L}$ (90430)], no significant differences were observed. However, at 3 months, the insulin levels were significantly lower in the metformin group $[110 \mathrm{pmol} / \mathrm{L}$ (75-299)] than in the control group [165 pmol/L (80340)] $(\mathrm{P}<0.05)$.

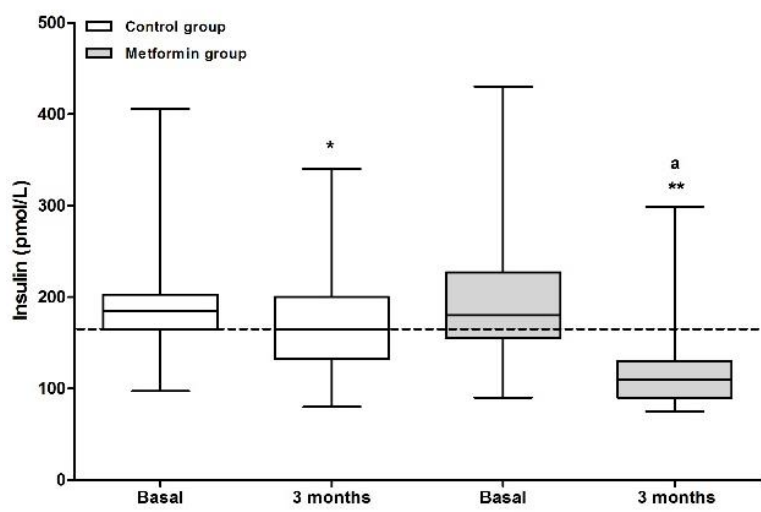

Fig. 3. Comparison of the blood insulin concentration of dogs with hyperadrenocorticism, with or without metformin treatment, at basal time and after 3 months of treatment. * $\mathrm{P}$ $<0.05$; *** $\mathrm{P}<0.001$; ${ }^{\mathrm{c}} \mathrm{P}<0.05$ vs. 3 months of control group. The dotted line indicates the upper limit of the reference range $(173 \mathrm{pmol} / \mathrm{L})$.

For the intragroup variation, insulin levels were significantly decreased after 3 months of treatment both in the control group $(\mathrm{P}<0.05)$ and in the metformin group $(\mathrm{P}<0.01)$, with the most pronounced decrease observed in the metformin group.

When comparing the basal time UCCR between the groups, no significant differences were observed. The UCCR decreased significantly after 3 months of treatment in both groups $(\mathrm{P}<0.001)$ (Table 1$)$.

Homeostatic model assessment (HOMA) for insulin sensitivity and $\beta$-cell function

At basal time, the HOMA insulin sensitivity $_{\text {(Fig. 4) did not }}$ show any significant differences between the groups.

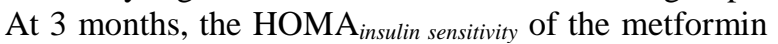
group was higher than the control group $(\mathrm{P}<0.05)$. For the intragroup variation, the HOMA $\mathrm{Hnsulin}_{\text {sensitivity }}$ was significantly increased at 3 months in both the control group $(\mathrm{P}<0.01)$ and the metformin group $(\mathrm{P}<0.001)$, with the most pronounced increase observed in the metformin group.

At basal time, the HOMA -cell function $_{\text {(Fig. 4) showed no }}$ significant differences between the groups. At 3 months, the $\mathrm{HOMA}_{\beta \text {-cell function }}$ of the metformin group was lower than the control group $(\mathrm{P}<0.05)$. In regard to intragroup variation, the $\mathrm{HOMA}_{\beta \text {-cell function }}$ decreased significantly at 3 months in both the control group $(\mathrm{P}<$ $0.01)$ and the metformin group $(\mathrm{P}<0.001)$, with the most pronounced decrease observed in the metformin group.

\section{Discussion}

In both dogs and humans with HAC, the comorbidities associated with hypercortisolism (hypertension, nephropathy, pulmonary thromboembolism, pancreatitis and diabetes mellitus) are the cause of patient death (Nichols, 1997; Ferraú and Korbonits, 2015; Miceli et al., 2017). 

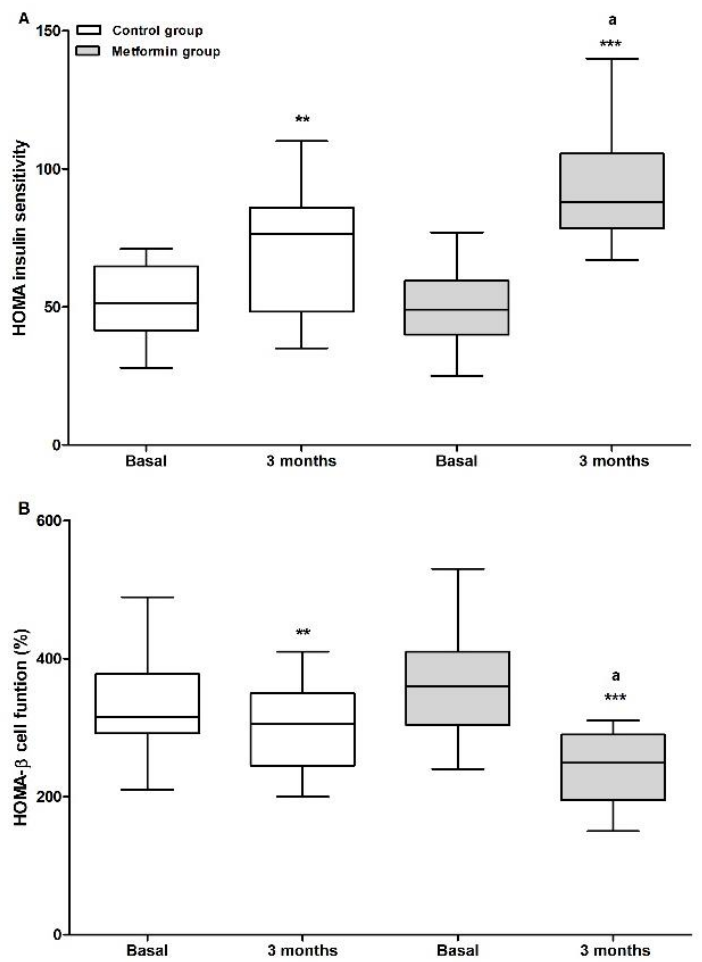

Fig. 4. Homeostatic model assessment (HOMA) for insulin sensitivity (A) and $\beta$-cell function (B) in dogs with hyperadrenocorticism, with or without metformin treatment, at basal time and after 3 months of treatment. (A): (**: P < $0.05)$ and (***: $\mathrm{P}<0.001) ; 3$ months vs basal intragroup; (a: $\mathrm{P}<0.05)$ vs 3 months of control group. (B): $(* * \mathrm{P}<0.01)$ and (*** $\mathrm{P}<0.001) ; 3$ months vs basal intragroup; $(\mathrm{a}: \mathrm{P}<0.05)$ vs 3 months of control group.

Therefore, therapies should not only be aimed at reducing hypercortisolism, but also at the prevention and/or control of comorbidities that may occur in the short- or long-term if the metabolic disorders associated with HAC are not normalised. Paradoxically, even after reducing hypercortisolism, the adverse effects of comorbidities associated with excess glucocorticoids can persist for several months (Barahona et al., 2009, 2010). A previous study by our group reported that the use of insulin detemir at low doses helped control the metabolic disorders associated with HAC, preventing the development of diabetes mellitus (Miceli et al., 2012). Similarly, in the present study, we observed that metformin was associated with decreased blood glucose, triglycerides and total cholesterol concentrations in dogs with HAC. In diabetic humans, it is known that metformin treatment decreases fasting hyperglycaemia, and to a lesser extent, postprandial hyperglycaemia, without increasing the risk of hypoglycaemia (Natali and Ferrannini, 2006; Aroda et al., 2015). In dogs, Chu et al. (2000) demonstrated that metformin is effective for decreasing hepatic glucose production, not so much by inhibiting gluconeogenesis, but rather by reducing glycogenolysis. The mechanism of action of metformin remains controversial, and it is not currently known exactly which receptor it binds. However, several studies have shown that metformin acts on AMPK (cAMP-activated protein kinase), an enzyme complex that is activated by increasing the AMP:ATP ratio (Rena et al., 2013; Foretz et al., 2014; Hongying and Ling, 2016). In contrast, some dogs with HAC that were not treated with metformin showed increased levels of glucose and triglycerides, despite having started the treatment for HAC. These increases may be due to individual differences of each dog to either the severity of the disease, resistance to therapy with ketoconazole or cabergoline, or persistence of the adverse effects of hypercortisolism (Vegiopoulos and Herzig, 2007; Castillo et al., 2008; Barahona et al., 2010; Miceli et al., 2012, 2017). To date, no studies have described the effects of metformin in dogs with HAC, but there have been several reports in diabetic cats. Nelson et al. (2004) evaluated the use of metformin to treat cats with diabetes mellitus, obtaining satisfactory results only in animals with a good insulin reserve. This is also the case for dogs with HAC that also present insulin resistance and hyperinsulinism (Montgomery et al., 1996; Miceli et al., 2014), which explains why the insulin-sensitising effect of metformin would be useful. Treatment of HAC with ketoconazole and cabergoline was found to be effective for reducing UCCR, and thus, controlling the clinical signs of the disease. Once hypercortisolism is controlled, the degree of hyperinsulinism, insulin resistance (indicated by increased HOMA $_{\text {insulin sensitivity }}$ ) and pancreatic $\beta$-cell functionality (indicated by decreased $\mathrm{HOMA}_{\beta \text {-cell function }}$ ) is simultaneously decreased. In this study, we used ketoconazole rather than retinoic acid (isotretinoin 9-cis) (Castillo et al., 2006) because patients receiving retinoids may present dyslipidaemia as an adverse effect (Lilley et al., 2013). The most interesting observation of the current study was that the administration of metformin, combined with ketoconazole treatment for HAC, caused a further reduction in the hyperinsulinism and insulin resistance of patients, as well as improved pancreatic $\beta$-cell functionality. By reducing hepatic glucose production (Chu et al., 2000; Hongying and Ling, 2016), metformin indirectly decreases the insulin requirement to maintain glycaemic homeostasis. Furthermore, due to its insulin-sensitising effects on adipose tissue and skeletal muscle (Natali and Ferrannini, 2006), metformin also decreases the peripheral insulin resistance in dogs with HAC. The use of metformin in dogs with HAC was associated with the same adverse effects observed in humans, including diarrhoea, inappetence and vomiting (Hostalek et al., 2015). No lactic acidosis or haematological disorders were 
observed, at least 3 months after therapy. Adverse gastrointestinal effects were controlled by gradually increasing the metformin dose. When the gradual dosage of metformin and the contraindications in humans, such as liver and kidney disease (Foretz et al., 2014; Hostalek et al., 2015), are considered, metformin represents a drug that can not only effectively improve insulin sensitivity and reduce the glycaemia of humans, cats and dogs, but is also safe to use. For future research, the long-term effects of metformin and its beneficial effects on other systems or diseases, such as cardiovascular disease, obesity, inflammation or cancer, will be assessed (Mahmood et al., 2013). The implementation of metformin as an adjuvant therapy is effective for normalising and improving glycaemia, triglyceridaemia, cholesterolaemia and insulinaemia in dogs with HAC, at least within the first 3 months of treatment. In addition, metformin reduced the insulin resistance and improved the pancreatic $\beta$-cell function in dogs with HAC. Dogs represent an excellent model for HAC study, and the results obtained have an interesting potential for translation to human medicine.

\section{Acknowledgments}

This work was supported by a grant (code: 20720130100004BA) from University of Buenos Aires-UBACyT, Argentina.

\section{Conflict of interest}

The Authors declare that there is no conflict of interest.

\section{References}

American Diabetes Association. 2016. Standards of medical care in Diabetes. Diabetes Care 39(1).

Andrews, R. and Walker, B., 1999. Glucocorticoids and insulin resistance. Old hormones, new targets. Clin. Sci. (Lond) 96, 513-523.

Aroda, V.R., Christophi, C.A., Edelstein, S.L., Zhang, P., Herman, W.H., Barrett-Connor, E., Delahanty, L., Montez, M., Ackermann, R., Zhuo, X., Knowler, W.C., Ratner, R. and Diabetes Prevention Program Research Group. 2015. The effect of lifestyle intervention and metformin on preventing or delaying diabetes among women with and without gestational diabetes: the Diabetes Prevention Program outcomes study 10-year follow-up. J. Clin. Endocrinol. Metab. 100, 1646-1653.

Barahona, M.J., Resmini, E., Sucunza, N. and Webb, S.M. 2010. Diagnosis of cure in Cushing' s syndrome: lessons from long-term follow-up. Front. Horm. Res. 38, 152-157.

Barahona, M.J., Sucunza, N., Resmini, E., FernandezReal, J.M., Ricart, W., Moreno-Navarrete, J.M., Puig, T., Farrerons, J. and Webb, S. 2009. Persistent body fat mass and inflammatory marker increases after long-term cure of Cushing's syndrome. J. Clin. Endocrinol. Metab. 94, 3365-3370.
Castillo, V.A., Giacomini, D.P., Páez-Pereda, M., Stalla, J., Labeur, M., Theodoropoulou, M., Holsboer, F., Grossman, A., Stalla, G. and Arzt, E. 2006. Retinoic acid as a novel medical therapy for Cushing's disease in dogs. Endocrinology 174, 4438-4444.

Castillo, V.A., Gomez, N.V., Lalia, J.C., Cabrera Blatter, M.F. and García, J.D. 2008. Cushing's disease in dogs: Cabergoline treatment. Res. Vet. Sci. 85, 26-34.

Chu, Ch.A., Wiernsperger, N., Muscato, N., Knauf, M., Neal, D.W. and Cherrington, A.D. 2000. The acute effect of metformin on glucose production in the conscious dog is primarily attributable to inhibition of glycogenlysis. Metabolism 49, 1619-1626.

Di Dalmazi, G., Pagotto, U., Pasquali, R. and Vicennati, V. 2012. Glucocorticoids and Type 2 Diabetes: From Physiology to Pathology. J. Nutr. Metab. doi:10.1155/2012/525093.

Ferraú, F. and Korbonits, M. 2015. Metabolic comorbidities in Cushing's syndrome. Eur. J. Endocrinol. 173(4), M133-157.

Foretz, M., Guigas, B., Bertrand, L., Pollak, M. and Viollet, B. 2014. Metformin: From Mechanisms of Action to Therapies. Cell Metabol. 20, 953-966.

Geerling, J.J., Boon, M.R., van der Zon, G.C., van den Berg, S.A., van den Hoek, A.M., Lombe' s, M., Princen, H.M., Havekes, L.M., Rensen, P.C. and Guigas, B. 2014. Metformin lowers plasma triglycerides by promoting VLDL-triglyceride clearance by brown adipose tissue in mice. Diabetes 63, 880-891.

Gomes Pöppl, A., Comparsi Coelho, I., Alves da Silveira, C., Bianchini Moresco, M. and Luiz Carvalho de Carvalho, G. 2016. Frequency of Endocrinopathies and Characteristics of Affected Dogs and Cats in Southern Brazil (2004-2014). Acta Sci. Vet. 44, 1379.

Herman, W.H., Hoerger, T.J., Brandle, M., Hicks, K., Sorensen, S., Zhang, P., Hamman, R.F., Ackermann, R.T., Engelgau, M.M., Ratner, R.E. and Diabetes Prevention Program Research Group, 2005. The cost-effectiveness of lifestyle modification or metformin in preventing type 2 diabetes in adults with impaired glucose tolerance. Ann. Intern. Med. 142, 323-332.

Hess, R.S., 2010. Insulin resistance in dogs. Vet. Clin. North. Am. Small. Anim. Pract. 40, 309-316.

Hongying, A. and Ling, H. 2016. Current understanding of metformin effect on the control of hyperglycemia in diabetes. J. Endocrinol. 228(3), R97-106.

Hostalek, U., Gwilt, M. and Hildemann, S. 2015. Therapeutic Use of Metformin in Prediabetes and Diabetes Prevention. Drugs 75, 1075-1094. 
Ishino, H., Hara, Y., Teshima, T., Tanaka, S., Takekoshi, S., Nezu, Y., Harada, Y., Yogo, T., Sako, T., Koyama, T., Teramoto, A., Osamura, R. and Tagawa, M. 2010. Hypophysectomy for a Dog with Coexisting Cushing's Disease and Diabetes Mellitus. J. Vet. Med. Sci. 72, 343-348.

Kooistra, H.S. and Galac, S. 2012. Recent Advances in the Diagnosis of Cushing's Syndrome in Dogs. Top Companion Anim. Med. 27, 21-24.

Levy, J.C., Matthews, D.R. and Hermans, M.P. 1998. Correct homeostasis model assessment (HOMA) evaluation uses the computer program. Diabetes Care 21, 2191-2192.

Lien, Y.H. and Huang, H.P. 2008. Use of ketoconazole to treat dogs with pituitary-dependent hyperadrenocorticism: 48 cases (1994-2007). J. Am. Vet. Med. Assoc. 233(12), 1896-1901.

Lilley, J.S., Linton, M.F. and Fazio, S. 2013. Oral retinoids and plasma lipids. Dermatol. Ther. 26(5), 404-410.

Mahmood, K., Naeem, M. and Rahimnajjad, N.A. 2013. Metformin: The hidden chronicles of a magic drug. Eur. J. Intern. Med. 24, 20-26.

Matthews, D.R., Hosker, J.P., Rudenski, A.S., Naylor, B.A., Treacher, D.F. and Turner, R.C. 1985. Homeostasis model assessment: insulin resistance and $\beta$-cell function from fasting plasma glucose and insulin concentrations in man. Diabetologia 28, 412-419.

Mazziotti, G., Formenti, A.M., Frara, S., Maffezzoni, F., Doga, M. and Giustina, A. 2017. Diabetes in Cushing Disease. Curr. Diab. Rep. 17, 32. doi: 10.1007/s11892-017-0860-9.

Miceli, D.D., Cabrera Blatter, M.F., Gallelli, M.F., Pignataro, O.P. and Castillo, V.A. 2014. Involvement of glucagon-like peptide 1 in the glucose homeostasis regulation in obese and pituitary-dependent hyperadrenocorticism affected dogs. Res. Vet. Sci. 97(2), 211-217.

Miceli, D.D., Gallelli, M.F., Cabrera Blatter, M.F., Martiarena, B., Brañas, M.M., Ortemberg, L.R., Gomez, N.V. and Castillo, V.A. 2012. Low dose of insulin detemir controls glycaemia, insulinemia and prevents Diabetes Mellitus progression in the dog with pituitary-dependent hyperadrenocorticism. Res. Vet. Sci. 93, 114-120.

Miceli, D.D., Pignataro, O.P. and Castillo, V.A. 2017. Concurrent hyperadrenocorticism and diabetes mellitus in dogs. Res. Vet. Sci. 115, 425-431.

Montgomery, T.M., Nelson, R.W., Feldman, E.C., Robertson, K. and Polonsky, K.S. 1996. Basal and glucagon-stimulated plasma C-peptide concentrations in healthy dogs, dogs with Diabetes Mellitus, and dogs with Hyperadrenocorticism. J. Vet. Intern. Med. 10, 116-122.
Natali, A. and Ferrannini, E. 2006. Effects of metformin and thiazolidinediones on suppression of hepatic glucose production and stimulation of glucose uptake in type 2 diabetes: a systematic review. Diabetologia 49, 434-441.

Nelson, R.W., Spann, D., Elliott, D., Brondos, A. and Vulliet, R. 2004. Evaluation of the oral antihyperglycemic drug metformin in normal and diabetic cats. J. Vet. Intern. Med. 18, 18-24.

Nichols, R. 1994. Concurrent illness and complications associated with canine hyperadrenocorticism. Semin. Vet. Med. Surg. (Small Anim.) 9, 132-136.

Nichols, R. 1997. Complications and concurrent disease associated with canine hyperadrenocorticism. Vet. Clin. North Am. Small Anim. Pract. 27(2), 309-320.

Peterson, M.E., Altszuler, N. and Nichols, C.E. 1984. Decreased insulin sensitivity and glucose tolerance in spontaneous canine hyperadrenocorticism. Res. Vet. Sci. 36, 177-182.

Peterson, M.E., Nesbitt, G.H. and Schaer, M. 1981. Diagnosis and management of concurrent diabetes mellitus and hyperadrenocorticism in 30 dogs. J. Am. Vet. Med. Assoc. 178, 66-69.

Pivonello, R., De Leo, M., Vitale, P., Cozzolino, A., Simeoli, Ch., De Martino, M.C., Lombardi, G. and Colao, A. 2010. Pathophysiology of Diabetes Mellitus in Cushing's Syndrome. Neuroendocrinology 92(Suppl. 1), 77-81.

Rena, G., Pearson, E.R. and Sakamoto, K. 2013. Molecular mechanism of action of metformin: old or new insights? Diabetologia 56, 1898-1906.

Schäcke, H., Docke, W.D. and Asadullah, K. 2002. Mechanisms involved in the side effects of glucocorticoids. Pharmacol. Ther. 96, 23-43.

Van Raalte, D.H. and Diamant, M. 2014. Steroid diabetes: from mechanism to treatment? Neth. J. Med. 72(2), 62-72.

Van Raalte, D.H., Ouwens, D.M. and Diamant, M. 2009. Novel insights into glucocorticoid-mediated diabetogenic effects: towards expansion of therapeutic options? Eur. J. Clin. Invest. 39, 81-93.

Vegiopoulos, A. and Herzig, S. 2007. Glucocorticoids, metabolism and metabolic diseases. Mol. Cell Endocrinol. 275, 43-61.

Verkest, K., Fleeman, L., Rand, J. and Morton, J. 2010. Basal measures of insulin sensitivity and insulin secretion and simplified glucose tolerance tests in dogs. Domest. Anim. Endocrinol. 39, 194-204.

Zhou, G., Myers, R., Li, Y., Chen, Y., Shen, X., FenykMelody, J., Wu, M., Ventre, J., Doebber, T., Fujii, N., Musi, N., Hirshman, M.F., Goodyear, L.J., Moller, D.E. 2001. Role of AMP-activated protein kinase in mechanism of metformin action. J. Clin. Invest. 108, 1167-1174. 